\title{
Experimental technology for harvesting the cotton yield
}

\author{
$I_{\text {Gorlova }}{ }^{1, *}$ and $T$ Khalmuradov ${ }^{1}$ \\ ${ }^{1}$ Tashkent State Agrarian University, University str., 2, Tashkent province, 100140 Uzbekistan
}

\begin{abstract}
This paper presents the results of research on the choice of the type and modes of operation of the experimental brush-slatted working body for collecting the maturated part of the cotton crop. The calculation of the forces acting on the remains of the cotton crop at separation from the cotton stalk is presented. The schemes of the combination of various types of experimental working bodies at increased speeds of the machine are determined. In conclusion, the results of calculating the economic efficiency of harvesting crop residues with brush-slatted working bodies are presented.
\end{abstract}

\section{Introduction}

In recent years, a radical improvement in the structure of agriculture has been carried out in Uzbekistan. A course has been set for carrying out agrarian reform. The area under crops for forage and food crops has been expanded by reducing the area under cotton $[1,3,6]$.

Cotton growing is based on the new economic system through rent, family and individual entrepreneurship, and farms. Economic prerequisites are being created to increase interest in increasing cotton production. Moreover, at present, there is an acute issue of increasing cotton production, mainly by increasing its yield [2, 4]. An important condition for this is the material and technical base of cotton growing, which ensures high quality products, high labor productivity and low production costs, and new progressive technologies $[5,6]$.

At the republican meeting of cotton growers, it was pointed out the need to improve equipment for agriculture and increase its competitiveness by modernizing the equipment produced, increasing its technical level, quality and reliability $[4,5,7]$.

In the cotton industry, it is planned to complete the comprehensive mechanization of the production of raw cotton. This task is not only urgent, but also problematic.

One of the most important links in the completion of the comprehensive mechanization of cotton growing is the widespread use of machines in the collection of the entire cotton crop grown, which will sharply increase the productivity of cotton growers and reduce the cost of a crop unit $[7,8]$.

At present, the harvesting of the uncovered part of the crop is fully mechanized. In the complex mechanization of the harvest of raw cotton, an important technological process is the harvesting of crop residues from bushes with poultry harvesting machines $[8,9]$.

* Corresponding author: irina.gorlova59@mail.ru 
The cultivated part of the cotton crop is harvested in the late autumn period. Under these conditions, clearing the fields from harvest remnants in a short time is of particular importance, because it determines the optimal timing of autumn plowing - the basis of the next year's harvest $[1,2]$.

Of the total amount of raw cotton harvested annually, the proportion of harsh depends on the weather conditions of the year, the type of variety, and the agricultural technology of cotton cultivation [10].

The question of mechanized harvesting of the harsh part of the cotton crop is currently being solved by using special cotton pickers. The portion of the cotton crop was harvested by serially produced semi-mounted cotton pickers SKO-2.4 and SKO-3.6 [4]. However, they did not meet the requirements for productivity and completeness of collection (no more than $80-85 \%$ ), there was a low and forward speed of these machines, amounting to only $1.2-1.5 \mathrm{~m} / \mathrm{s}$. At the same time, with an increase in the forward speed of the machine, the productivity, although it increased, but the completeness of collection fell to $80-70 \%$ [11].

Cotton pickers mainly collect crop residues in the form of half-open and closed bolls, the raw cotton of which is of lower quality (industrial grade 4-5) than from open bolls (commercial grade 1-3) [2]. But in the cotton bushes, after processing them with a cotton picker, there are still a significant amount of individual slices and bolls (picks) remaining in the open boxes, and sometimes even whole open boxes, and high quality cotton, which is mostly hand-picked. Therefore, at the present stage, requirements are imposed on the harvest residues of cotton pickers so that their working bodies remove the entire remaining harvest from the bushes, i.e. not only half-opened and closed boxes, but also those left after the work of cotton pickers, both open individual boxes, and picks and individual cotton wedges [1, 12].

Attempts to harvest the remnants of the cotton harvester by combining operations to collect the open and cultivated parts of it have not yet yielded encouraging results and have not received support in production conditions [2].

Severe weather conditions during the harvesting period in some years with heavy precipitation in the form of rain and snow, as well as the presence of green bolls on the bushes exclude the possibility of using bulky cotton pickers to harvest cotton. In addition, the use of sophisticated and expensive cotton pickers in the collection of low-yielding dried maturated part of cotton is not economically profitable, compared to the remainder of the harvest with a cotton picker. Residues of the harvest cotton harvester can be used in extreme conditions of the harvesting period $[13,14]$.

It is known that one of the main ways to increase labor productivity in mechanized cotton picking is to increase the forward speed of the machine [1, 2]. But an increase in the forward speed of the harvest residues of the cotton picker without changing the parameters of its harvesting working bodies leads to a disruption in the technological process of the machine's operation: the cotton bushes bend in front and the working rollers do not have time to process them along their entire height. Because of this, the already low completeness of harvest decreases, slaughter is observed, leading to a halt in the process of removing crop residues from the bush [4].

Based on the foregoing, the goal is to conduct a study to find an improved rational working body for collecting cotton crop residues from bushes.

With the transition to a higher speed, it is necessary to improve the existing or create new working bodies of the harvest residues of the cotton picker, which would ensure its stable operation without reducing the quality indicators. Therefore, this research was aimed at solving this issue, the results of which are presented in this article. 


\section{Analysis of up-to-the-date technology for harvesting cotton}

Mechanized cotton harvesting technology is mainly used in the United States, where up to $98 \%$ of raw cotton, including all seed cotton, is harvested by machines, incl. pickers 60 $70 \%$, strippers up to $30-40 \%$, pickers up to $1.0 \%$.

The companies John Deere, Heston, International Harvester, Minnapolio-Mollein, Oliver-Cockshatt, Case are engaged in the development and production of cotton pickers [15].

In the USA, as a rule, one or two machine cotton picks are carried out. There is no separate operation to collect the remains of the cotton crop from the bushes. The raw cotton remaining after machine harvesting on the bushes and fallen to the ground is not picked up, but plowed into the soil with crushed stems. Harvesting this part of the crop is considered economically unprofitable. It is recommended to start picking cotton at a cotton moisture content of no more than $10 \%[15,16]$.

Two types of machines are used for cotton harvesting: spindle and stripper brush-type harvesters. Horizontally - by spindle machines (pickers) the crop is harvested in two passes with the initial opening of at least 60-70 boxes. Combines of the brush type (strippers) harvest the entire crop in one pass. Brush-type stripper harvesters practically perform the same operations on harvesting the entire grown crop as our specialized harvest residues cotton pickers SKO-2.4 and SKO-3.6 perform on harvesting crop residues [4].

The advantages of the stripper harvester are simplicity, reliability and ease of maintenance, cost-effectiveness, increased speed of movement across the field, high completeness of harvesting with fiber retention [16].

One of the significant disadvantages of strippers is the significant contamination of the raw cotton they collect. This requires additional costs for its cleaning, which is mainly on a specially stationary cleaner.

All new modifications of stripper combines are two and four-row. They are mainly used in narrow row $(70-75 \mathrm{~cm})$ row spacings. The John Deere company produces a more efficient mounted cotton harvester brush harvester, designed to harvest cotton at the same time in one pass from four or five row spacings $96-101 \mathrm{~cm}$ wide $[2,15]$.

Currently, the company produces mainly two-row roller machines, which are hung behind the tractor and collect the heap in a trailer transported by the same tractor. There is a model of trailed and self-propelled vehicles. Since row spacings in the United States are between 91 and $112 \mathrm{~cm}$, the harvesters of these machines can line up to work in the specified row spacings [15].

The cleaning device consists of two cylindrical, conical brush-slat drums with a diameter of $150 \mathrm{~mm}$ at the top, up to $120 \mathrm{~mm}$ at the bottom and two longitudinally screw conveyors also made conically with a diameter of $170 \mathrm{~mm}$ - at the bottom, and fixed in the lower supports, which differ from the serial ones in their reduced dimensions [1].

Typical working speed of the stripper is from 8 to $11 \mathrm{~km} / \mathrm{h}$. A transverse auger is located under the devices, which consists of a right-handed auger, at the end of which there is an ejected blade, and a screw casing. There is an unloading window on the right side of the auger casing. A suction pipeline is connected to the unloading window and is connected to a fan mounted on the hopper of the self-propelled chassis [1].

All mechanisms are driven from the chassis PTO shaft. The bevel transfer gearbox, made specifically for new cotton pickers, gets its rotation from the chassis PTO shaft. From it, through the intermediate rollers by coupling half couplings, the torque is transmitted by the gearboxes of the harvesting devices, and they are made by a new brush-slat working body. From the gearboxes of rotation it is transmitted by the working body and the augers of the harvesting device. From the drive shaft of the harvesting devices through the 
overload clutch to the counter drive and from it by the chain transmission of rotation is transmitted to the transverse auger $[2,16]$.

The working bodies in the cleaning devices of most machines are two rotating brush rollers, each of which is generally $160 \mathrm{~mm}$ in diameter. The brush rollers are made of synthetic nylon fabric, 0.3-0.6 mm in diameter [2]. Its advantage is that it allows an infinite number of bends has no stability limit, is not prone to aging from the effects of meteorological conditions and time.

The brush rollers in the cleaning machines are installed at an angle of 30 degrees, their length for various models ranges from 1,015 to $1,675 \mathrm{~mm}$ [4]. Due to the fact that the brush rollers do not have an impact on the bush, the completeness of the cotton harvest from the bushes is much higher, and the collected heap does not contain large branches and stems. This makes it much easier to further clean and recycle. Most of the machine models have a box separator. The machines are not equipped with cleaning devices; this is due to the high efficiency of stationary cleaning equipment at refineries $[2,4]$.

The technological process of work of strippers is as follows: two harvesting devices are hung on the right and left sides of the tractor. The devices have two working rollers, which rotate towards each other, forming a working slot. The working roller consists of a crankshaft, on which a plastic or rubber jacket is worn, fixed to the shaft with screws. On both sides of the working slot there are conveying augers. At the bottom of the devices there is a transverse auger, which receives the heap from the devices and transports it to an inclined scraper elevator, which dumps the heap into the trailer [3].

The change in the thickness of the rubber strips in the work roll is controlled by the length of the protrusion and hence its flexibility. The strips are made in the form of elastic strips made of plastic or synthetic rubber. They are resilient enough to strike the capsules with enough force to tear off the stem of a mature capsule. Cleaning devices with working bodies of this type are installed on machines from Oliver-Kokshatt, John Deere and others $[15,16]$.

Consequently, the maturated portion of the US cotton crop is mostly harvested at the same time as the exposed portion of the crop by strippers. The main working bodies of the harvesting devices of such machines are, as in our crop residues cotton pickers, corrugated (metal) or brush rollers, consisting only of nylon brushes and rubber strips.

A distinctive feature of harvesters in the United States is that they harvest heavily weedy crops. Cleaning of the harvested crop by machines, both spindle and brush type, is carried out on special stationary cleaners that provide high-quality cleaning.

\section{Agrotechnical requirements for agricultural machineries for harvesting the maturated portion of cotton yield}

According to standard flow charts for the production of raw cotton for Uzbekistan, the cotton harvesting technology includes three main operations: mechanized two-fold harvesting of opened raw chlorine, which is supposed to be carried out by machines; mechanized harvesting of cotton harvest residues on the entire area of the machine for harvesting raw cotton, using four-row harvest residues of cotton harvesting machines SKO2.4, SKO-3.6; selection of cotton that has fallen to the ground, carried out by hand. The whole range of works is planned to be carried out from September 20 to November 5 .

Such a technology for harvesting cotton has developed historically due to the fact that in the irrigated cotton growing zone in the autumn, weather conditions are extremely difficult due to heavy precipitation in the form of rain and snow and a sharp drop in temperature.

The onset of an early cold snap in autumn delays the ripening of cotton and makes it difficult to carry out high-quality preparation of cotton fields for mechanized harvesting. 
Due to the high moisture content of the soil and raw cotton in the opened boxes, the timing of harvesting the opened part of the crop by cotton pickers is violated.

In production conditions, the harvesting of the opened part of the cotton crop by cotton pickers is usually carried out in two or three, and in some cases, more harvesting frequency.

After working with cotton pickers, a part of the crop remains on the cotton bushes in the form of slices, flies, half-open and unopened bolls, usually referred to as "harvest residues" or "harsh". "Leftover harvest", in our opinion, is more acceptable to this part of the harvest, because along with half-open and closed bolls, representing the mature crop, includes opened cotton left by the cotton pickers on the bushes. It is recommended that this part of the crop be harvested with cotton pickers.

The proportion of the harsh' harvest varies depending on the agricultural technology used for growing cotton, the frequency and technology of harvesting the opened part of the crop, the meteorological conditions of the year and especially the weather conditions in the autumn harvesting period.

During mechanized harvesting of crop residues, the machine has to work in difficult conditions:

- a deformed cotton bush, due to the impact on it of both working bodies and the very passage of the cotton picker;

-the presence on the bushes, along with half-open and closed bolls, open bolls with and without cotton, as well as with the remaining individual cotton wedges and separate cotton bolls;

- unfavorable weather conditions.

Therefore, a cotton picker must have working bodies capable of collecting all the crop residues of cotton bushes and at the same time having indicators that meet agrotechnical requirements. In addition, it must have high productivity in order to ensure the harvesting of crop residues in the shortest possible time and to ensure that the cotton stalks can be harvested and the plowing can be raised before the onset of inclement weather.

\section{Calculation of the forces acting on the cotton crop residues when detached from the cotton stalk}

In the harvester, two parallel rollers, being inclined to the horizon, rotate around their axes in different directions and when the machine is moving [2].

When brushing bushes, due to the fact that the working gap between the rollers is less than the diameter of the capsule and the rollers rotate upward, the capsules cannot pass through the gap and move for some time with the rollers, sliding along their surface. Branches with bolls are straightened and attracted. In this case, the tensile force and the friction force increase. At the moment when the resultant, pushing the box of forces, becomes more important than the bond strength of the box with the bush, the box breaks off from the bush. Consider the forces acting on a boll, working rollers when they are torn off the cotton stalk. Let us determine the forces acting on the cotton crop residues when they are torn off the cotton stalk $[1,2,4]$. We decompose the weight force $G$ into two components: the rolling force $\mathrm{G}_{1}$, directed along the axis of the shaft, and the force of normal motion $G_{2}$, directed along the normal to the surface of the shaft (1).

$$
G_{1}=G \sin \alpha ; G_{2}=G \cos \alpha ;
$$

Where, $\mathrm{G}$ - weight of cotton crop residues and $\alpha$ - the angle of inclination of the shaft to the horizon. 
At the moment of separation of the cotton crop residues from the stem, a stem reaction occurs, which depends on the moisture content of the stem, the cotton variety, and the reaction is directed along the stem, which is inclined at an angle (Fig. 1).

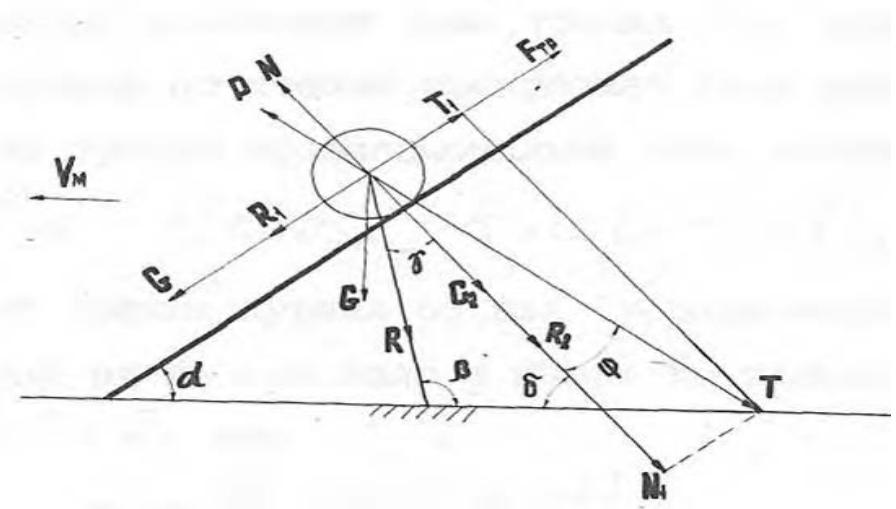

Fig. 1. Diagram of forces acting on a half-opened harvesting box.

Just like the force $\mathrm{G}$, let us expand the force $\mathrm{R}$ into two components directed along the axis of the shaft $R_{1}$ and along the normal to the surface of the shaft $R_{2}$ (2). To do this, it is necessary to determine the angle $\mathrm{y}$.

$$
R_{1}=R \cos (\alpha-\beta) ; R_{2}=-R \sin (\alpha-\beta)
$$

In the direction of the normal to the shaft, the resulting force $\mathrm{N} 1$ acts on the cotton crop residues, equal to the sum of $G_{2}$ and $R_{2}$, that is (3):

$$
N_{1}=G_{l} \cos \alpha-R \sin (\alpha-\beta)
$$

At the moment of separation of the cotton crop residues from the stem, the separation occurs due to the inclined movement of the inclined shaft, the effect of which on the cotton crop residues can be interpreted as the action of a wedge, a friction force $F_{\text {fr }}$ occurs (4).

It is known that the frictional force is proportional to the force of normal pressure:

$$
F_{\text {fr }}=f x N_{l}=f[G \cos \alpha-R \sin (\alpha-\beta)]
$$

Where, $f$ - the coefficient of friction of the cotton crop residues against the shaft (averaged).

Force $F_{\mathrm{fr}}$ is directed along the axis of the shaft and has the opposite direction to the sum of forces (5):

$$
F=G_{I}+R_{l} \text { or } F_{1}=G \sin \alpha-R \cos (\alpha-\beta)
$$

\section{Results and discussion}

Experimental studies were carried out according to the research program:

1. Study of the characteristics of the working environment of the crop residues of the cotton picker.

2. Selection and substantiation of the object of research of the scheme of the combination of working elements in a harvesting device with inclined roller working bodies. 
3. Study of the technological process of collecting the remains of the harvest of raw cotton from the bushes at increased speeds of the harvesting machine.

4. Determination of the quantitative and qualitative indicators of the experimental harvesting body on the collection of the crop residues (harsh) cotton depending on the parameters and operating modes: roller diameter; speed modes; the angle of inclination of the working device to the horizon.

5. Optimization of the main parameters of the experimental working body when collecting residues at high speeds.

6. Determination in production conditions of agrotechnical, operational-technological and energy indicators during the operation of the experimental harvesting device at increased speeds of the machine.

Experimental rollers were made with the ability to study various types of surfaces of the working body: brush, slat, and brush-slab.

Laboratory-field experiments were carried out in experimental fields using a laboratory-field installation for collecting crop residues.

When determining the agrotechnical, technical, operational and energy indicators of the operation of the harvesting apparatus with brush-slatted working bodies, the work was compared with the operation of a serial harvesting apparatus with corrugated rollers mounted on a common frame, but having separate bins for collecting cotton crop residues from bushes from a serial apparatus and from the experimental.

The working gap between the rollers is set depending on the average diameters of bolls and was $18-20 \mathrm{~mm}$.

Laboratory experiments were carried out in the background after the second machine harvesting of the uncovered part of the raw cotton crop. For the experiment, we chose areas with rectilinear rows, without lodged bushes and transverse irrigation ditches, with a rut length of at least $100 \mathrm{~m}$. Before the pilot machine passes, the fallen open cotton and the boxes knocked down during the previous two passes of the cotton pickers are manually picked up from the ground. The agrotechnical characteristics of the field are recorded on the plots allotted for the experiment.

The experimental apparatus is hung on a serial cotton picker SKO-3.6, with the fortifier turned off. The influence of the type of the surface of the working body and the high-speed mode of operation on its quality indicators was investigated in the fields of the experimental farm UzMEI on medium-fiber cotton of the S-6524 variety. The average height of the bushes was $100.5 \mathrm{~cm}$, the width was $34.3 \mathrm{~cm}$, the plant density was 76,600 per ha.

Experiments to optimize the parameters of the brush-slatted working body were carried out in laboratory-field conditions on sowing medium-fiber cotton varieties 4C-4880. The average plant height was $103.5 \mathrm{~cm}$; width $-20.6 \mathrm{~cm}$, planting density $-86,600$ per ha; yield - 3.8 quintals/ha.

Laboratory and field experiments to determine agrotechnical indicators are carried out in five repetitions according to OST 70.8. "Machines for harvesting raw cotton and cotton stalk." Test program and methods. The work was carried out in the fields with the cultivation of cotton varieties one "Tashkent-1", C-4880 and C-6524. Evaluation criteria of the studied working body for harvesting crop residues were completeness of collection in the bunker; the amount of cotton left on the bushes and upholstered in the ground; moisture and contamination of the harvested raw cotton, and the strength of the raw cotton. The type of cotton fiber collected by serial and experimental working bodies was determined by the method of fiber air permeability using an LPS-4 device.

It is known that the power is related to the torque dependence (6) [1]:

$$
N=1.027 M_{i} n \eta
$$


Where: $\mathrm{M}_{\mathrm{i}}$ - the corresponding value of the torque for the drive of the harvesting device; $\mathrm{n}$ - the number of revolutions of the roller, $\min ^{-1}$; and, $\eta$ - efficiency chain transmission0.97 .

To determine the magnitude of the torque of the drive shaft of the working device, a strain gauge unit was developed and manufactured at the experimental plant UzMEI [2].

In this strain gauge unit, the strain-star, mounted on ball bearings on the strain-link bushing, through the strain-link bushing lever transfers the rotation from the electric motor located on the laboratory setup to the drive shaft of the working body of the apparatus (Fig. 2).

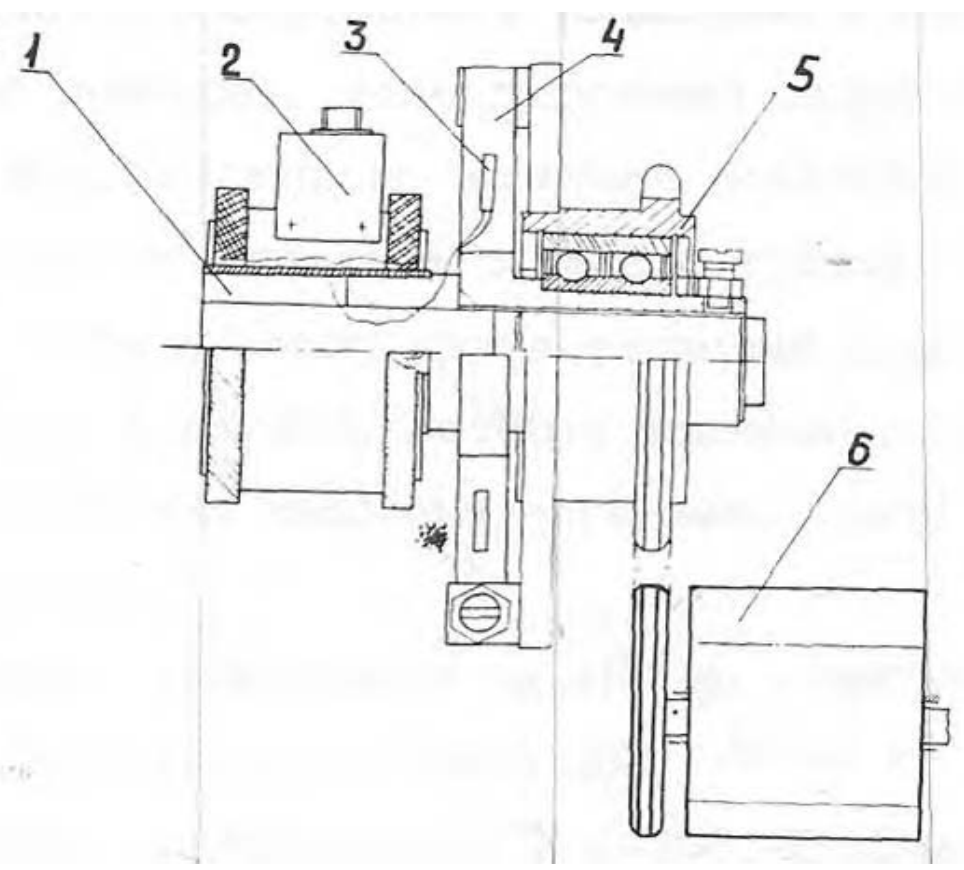

Fig. 2. Strain gauge measurement scheme: 1-strain gauge, 2-current collector, 3-sensors, 4-sleeve lever, 5-strain star, and 6-drive shaft of the working body.

The lever is a bend of equal resistance. Dynamic resistance sensors are glued to the grinding surface of the lever, which make up the measuring half-bridge. At the moment of bending, the sensors deform, changing their resistance.

A change in the resistance of the conductor causes an imbalance in the bridge. The signal is fed through the mercury-amalgamated "Trap-50" 2 to the TA-5 amplifier and then to the galvanometers of the $\mathrm{N}-04154$ light oscilloscope. The recording of the rotational speed of the working body of the pick-up was controlled by induction marking of the revolutions.

To determine the power consumption to drive the crop residues of the cotton picker, the change in the torque value was recorded with an N-115 oscilloscope. To determine the scale of the obtained oscillograms, the measuring bridge was calibrated before and at the end of the experiments [4].

The technique of strain gauging consisted in the following: during idle operation of the apparatus, after a steady state of normal operation, there was a recorder of the device. After receiving the oscillogram of idling, a rack with cotton bushes was fed into the working slot of the harvesting device. An oscillogram was also recorded during the operation of the apparatus with brush stripping. The difference between the two records of the ordinate values showed the resistance of the apparatus, which arises when combing cotton bushes 
with the corresponding working organs. The experiments were carried out in five repetitions.

Let us establish the effect on the technological process of picking raw mature cotton the surface of the experimental working organs: brush, slat and brush-slat, their layout (Fig. $3)$.
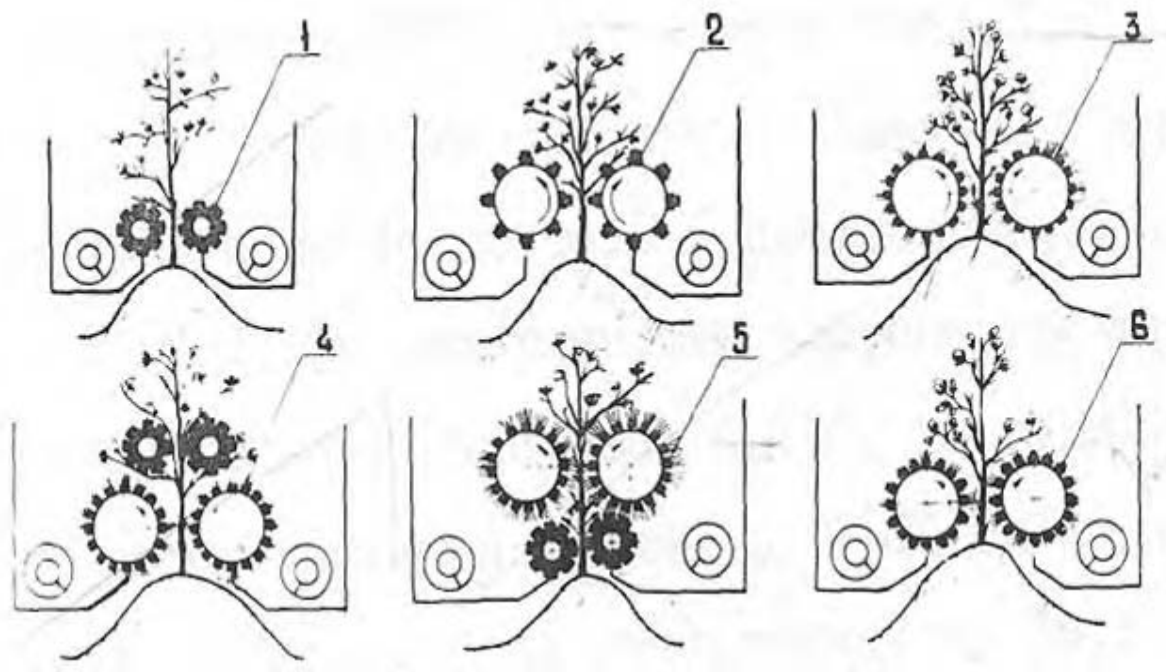

Fig. 3. Scheme of harvesting devices for collecting cotton crop residues from bushes, options for working bodies: 1- corrugated rollers (serial), 2- slatted rollers, 3- brush rollers, 4- brush rollers under corrugated rollers, 5 - brush rollers over corrugated rollers, and 6 - brush-slatted rollers.

Experimental brush-slatted working bodies are replaceable rollers, on the surface of which brushes were arranged alternating in the order of six rows (from the removable drum of a cotton picker) and six rows of strips made of rubberized material (Fig. 3). In addition, in order to identify the effect of separate brushes and strips on the technological process, variants were carried out with the installed in the cleaning device: only brush rollers and only slat rollers and combined brush-slat rollers. Variants of combining brush rollers as patrols with serial rollers were also tested when brush rollers were placed in one apparatus over serial corrugated rollers. The proposed design of the experimental cleaning device made it possible to install the brush rollers under serial corrugated rollers. The control for all the compared variants was the indices of serial corrugated beads of the AFB [1].

The results of laboratory and field tests show that such a scheme can increase productivity by $30-35 \%$ and the completeness of harvesting cotton crop residues up to $96-$ $97 \%$.

The annual economic effect from the operation of one machine in terms of crop residues with improved devices, determined by the equation, amounted to $10,616,800 \mathrm{UZS}$.

\section{Conclusions}

In summary, the studies carried out in the field showed that when working at an increased speed of movement, the crop residues of the SKO-3.6 cotton harvester out of all the tested schemes for combining various types of experimental working bodies, the best results in terms of such indicators as the completeness of the collection, the loss of cotton on the bushes and the ground according to the contamination of the collected heap of the part of the crop, experimental working bodies are provided, consisting of brush-slatted rollers. 


\section{References}

1. N. Kulmetov, I. Gorlova, Mechanization of Cotton Research, 11, 10 (2009)

2. I. Gorlova, Mechanization of Cotton Research, 8, 12 (2010)

3. S. Isaev, S. Khasanov, Y. Ashirov, T. Karabaeva, A. Gofirov, In E3S Web of Conferences, 244, 02012 (2021)

4. I. Gorlova, Mechanization of Cotton Research, 10, 13-14 (2013)

5. S. Isaev, S. Khasanov, Y. Ashirov, A. Gofirov, T. Karabaeva, In E3S Web of Conferences, 244, 02047 (2021)

6. N. Teshaev, B. Mamadaliyev, A. Ibragimov, S. Khasanov, InterCarto. InterGIS, 26(3), 324-333 (2020)

7. B. Sh. Matyakubov, Z. J. Mamatkulov, R. K. Oymatov, U. N. Komilov, G. E. Eshchanova, InterCarto, InterGIS, 26, 229-239 (2020)

8. N. Ch. Namozov, D. A. Kodirova, M. I. Usmonova, International journal of scientific \& technology research, 9(03), 5491-5493 (2020)

9. S. K. Isaev, R. U. Rakhmonov, S. S. Tadjiev, G. I. Gozeiv, S. Z. Khasanov, In IOP Conference Series: Earth and Environmental Science, 614(1), 012147 (2020)

10. R. A. Kulmatov, S. A. Adilov, S. Khasanov, In IOP Conference Series: Earth and Environmental Science, 614(1), 012149 (2020)

11. N. Sabitova, O. Ruzikulova, I. Aslanov, In E3S Web of Conferences, 227, 03003 (2021)

12. B. Alikhanov, M. Juliev, S. Alikhanova, I. Mondal, Groundwater for Sustainable Development, 12, 100548 (2021)

13. Y. Gafforov, R. Phookamsak, H. -B. Jiang, D. N. Wanasinghe, M. Juliev, Botany, 97(12), 671-680 (2019)

14. I. Musaev, A. Bokiev, M. Botirova, In E3S Web of Conferences, 227, 05004 (2021)

15. J. M. Bennett, N. P. Woodhouse, T. Keller, T. A. Jensen, D. L. Antille, Journal of Cotton Science, 19(2), 225-249 (2015)

16. W. B. Faulkner, J. D. Wanjura, R. K. Boman, B. W. Shaw, C. B. Parnell, Applied Engineering in Agriculture, 27(4), 497-506 (2011) 